\title{
The Relationship between Sociodemographic Characteristics of Dyslexic Children and their Higher Perceptual Functions
}

\author{
Heba Kadees Marzouk, Sanaa Habshy Abdel Megied Shaheen, Yasser Mohamed Bader El Deen Elserogy \\ \& Naglaa Abdel Megied Mohamed
}

Assistant lecturer of Psychiatric Nursing, Faculty of Nursing, Assiut University, Egypt.

Professor of Psychiatric Nursing, Faculty of Nursing, Alexandria University, Egypt.

Assistant professor of Psychiatry, Faculty of Medicine, Assiut University, Egypt.

Assistant professor of Psychiatric Nursing, Faculty of Nursing, Assiut University, Egypt.

\begin{abstract}
Dyslexia is a failure to read at expected level. The sociodemographic characteristics of dyslexic children is suggested to affect their perceptual function. Nurses have an important role in assessing children for any reading disability and help them to cope normally with any psychological distress. The aim of the study: identifying the relationship between sociodemographic characteristics of dyslexic children and their perceptual function Subjects and method: The study subjects were composed of 50 children (30 boys and 20 girls). The study was conducted at child outpatient clinic of Psychiatric Mental Health Hospital and psychiatric outpatient clinic of Assiut University Hospital during one year duration from $30^{\text {th }}$ November 2012 until $30^{\text {th }}$ November 2013. Childern were assessed through visual and auditory memory tests, in addition to Socio economic assessment scale. Results: there was a significant difference as regard sex in which females outperform males but there was no significant difference as regard the age, residence, and socioeconomic levels in relation to visual and auditory memory results. Conclusion and Recommendation: Only sex has a relation to the cognitive function of dyslexic children in which girls outperform boys. Intensive attention should be given to male dyslexic children to improve their cognitive function.
\end{abstract}

\section{Key words: Sociodemographic, Dyslexic children \& Higher perceptual functions.}

\section{Introduction}

Dyslexia is a failure to read at expected level, has been the focus of much discussion and research among physicians, educators, and psychologists. The problem was first addressed at the end of the current century, at which time it was referred to as "word blindness". Since then, there has been much disagreement about its definition (Rutter et al., 2012).

Dyslexia is the most common cause of difficulty of reading, writing, and spelling, one of every five students has some form of disability involving language, which is about fifteen to twenty percent of the population. Though with the high amount of dyslexic individuals, only one- third of those in school are getting help for their issue. The statistics for dyslexia are pretty much the same all around major places in the world, although the knowledge of the disability can vary depending on the educational level of the area. In less educated areas in the world, such as places in Egypt, people may not even know they have a learning disability or know any thing about them. This is not their faults; it is just because education is much lower in their area. Other less educated areas have this issue as well (Denton \&Mathes, 2014).

Efficient reading must call on three processes: one must retain the correct order of what has been read in order to understand the meaning of sentence: one must be able to name rapidly the written words seen on a whole word basis, and finally, one must analyze the individual sounds of the phonemes presented in the highly encoded co-articulation, in order to match them with the sequential regularity of the successive graphemes (VanHout, 2012).

Normally, females tend to do better in language related tasks and tend to do better at spatial tasks, that is why learning disabilities have a higher incidence among males, with a prevalence of male to female ratio of 3:1. Learning disabilities were highly represented in lower sociocultural class (illiteracy or elementary education), but less represented in the upper sociocultural class (university or post university level of education), and this emphasizes the role of sociocultural predisposition. The incidence of learning disability is related to the quality of schooling but if only environmental factors were responsible, a more equal sex ratio would be expected. The environment in which children are raised may affect behavior indirectly by altering brain development. Institutional confinement, neglect and child abuse can cause retarded intellectual development (Genschwind\& Galaburda, 2012., Farage et al., (2010) Hibert \& taylor, (2014) Das et al., 2012). 
Hibert\& Taylor, (2014) defined the higher perceptual functions as those function interfere with the individual capabilities to perceive the most complicated cognitive tasks such as visual and auditory memory, visual and memory discrimination and recognition

Orton's work in the 1930s, noted that visual perceptual, visual-spatial, or visual-motor deficits underlie reading disorder. He focused on two types of letter reversals, kinetic (for example, reading "was" for "saw" or "on" for "no") and static (for example, confusing $b$ and $d$ ). Such reversals led to the hypotheses that children with reading disorder experienced spatial disorientation or left-right discrimination difficulties (Helmuth, 2014).

Visual discrimination problems have often been associated with learning disabilities. Individuals with such problems may be unable to distinguish one visual stimulus from another e.g. between words such as "sit " and "sat" or letters such as "v" and "w" (Hallahan et al., 2012). Auditory discrimination problems may results in an inability to recall information presented verbally. Auditory association deficiencies may cause the person to be unable to associate ideas or information presented verbally. Difficulties in these areas cause school performance problems (Nix\& Shapiro, 2009).

Children with learning disabilities have different rather than deficient cognitive abilities. Attention problems have also been associated with learning disabilities. Such problems have often been clinically characterized by short attention span. Parents and teachers often note that their children with learning disabilities cannot sustain attention for more than a very short time (Hall\& Kimura, 2012).

Some of the characteristics which have been attributed to those with reading disabilities are in the area of cognition or information processing (Reid, 2007). Most neuropsychological theorists would agree that learning disabilities results from disturbed cognitive processes, or from an imbalance of the child's information processing abilities rather than from a generalized cognitive deficit Hynd\& Obrzut, 2009, Gordon, 2008).

At the level of cognitive modality (auditory, visual, tactile, kinesthetic), three primary types of dyslexia were identified, auditory, visual and mixed. Those with processing deficits (good auditorizors) write phonetically, the way the word sounds (visual dyslexics). Those with auditory processing deficits (good visualizes) write non- syllabic sequences of meaningless letters (auditory dyslexics)

(Kinsboune\& Warringon, 2010).

The cognitive stimulation in early childhood could be effective and cognitive training has improved intellectual performance. This ultimate purpose of cognitive remediation is to improve specific cognitive processes that underlie academic skills such as reading words. Other studies found that the scores following training program for perceptual functions skills are significantly better and showed that cognitive training techniques improve cognitive deficits such as successive processing and short term visual memory(Haywood\& Tappolog, 2009; Feurerstein, 2010; Bradley\& Bryant, 2011; Elstein, 2012, Mender et al., 2012).

\section{Subjects \& methods \\ Research Design}

This study followed a descriptive research design.

Setting

The study was conducted at the child outpatient clinic of Psychiatric Mental Health Hospital and psychiatric outpatient clinic of Assiut University Hospital

Subjects

All dyslexic children referred to child outpatient clinic of Psychiatric Mental Health Hospital and psychiatric outpatient clinic of Assiut University Hospital, both sexes and aged from 6 to 12 years old for one year from 30th November, 2012 to 30th November, 2013, were approached those accepted to participate in the study and give an informed oral or written consent from their parents. The studied sample consisted of 50 patients, (30) boys and (20) girls, 35 child from Psychiatric Mental Health Hospital and 15 child from psychiatric outpatient clinic of Assiut University Hospital.

\section{Tools of the study}

Three tools were used for data collection

Sociodemographic questionnaire

The structured interview questionnaire sheet consists of questions related to socio- demographic characteristics such as child's name, age, sex, school grade and address.

\section{Socio Economic Status Scale}

This scale was developed by Fahmy and Elisherbinim (1984) to assess the socioeconomic status of the family. It asses the family status based on 7 items. There are father's education, work, mother's education and work monthly income, crowding index and sanitation. The total score is summed up to 42 . Families who score between 42-36 considered of high social class; those who score between $35-27$ are considered as middle social class, those who score between 26-21 are considered low social class, those who score less than 21 are considered of very low social class.

Visual \& auditory memory test: The original visual memory test was developed by Dykman, (1993) Translation of the original visual memory test into Arabic language as well as carried its validation and standardization of has been done by professor Abdel- 
Rakeeb Elbehairy (professor of psychology-Faculty of education- Assiut University) and Abdel Kader Farrage ( professor of psychiatric medicine- Faculty of medicine -Assiut university).

\section{Avisual memory test (composed of 4 subtests)}

Visual discrimination: where the child is asked to circle around the correct letter, word or figure on the left column, that he sees in the right column.

Visual memory: where the child is given a card containing cards for 5 second and then is asked to draw it. This is repeated for 10 different cards.

Visuo- motor association: the child is asked to draw a line for completion of figures on the left side as figures shown in the right side of cards.

Recognition test: in which there are 10 different figures, letters, words and numbers to which child is asked to name each of them.

The auditory memory test (composed of $\mathbf{4}$ subtests)

Auditory discrimination: in which the child is requested to say whether the 2 words said to him are the same or not. Ten couples of words are said to him, some are the same whereas others are not.

Auditory memory: In which words are said to the child once and he is asked them to repeat number of words are different is numbers arranged from 2 words up to 6 words.

Auditory sequence: In which the examiner says numbers, letters or words in sequence and the child is asked to repeat them in the same sequence.

Auditory association: In which a word is said to the child in parts and he is asked them to say it as whole, only one chance was given to the child for each word. Methods of data collection

An official permission was granted from responsible authorities to carry out the study after explaining the purpose of study.

Sociodemographic data sheet was developed by the researcher.

The researcher assured voluntary participation of subjects and their privacy.

Confidentiality to each child also assured.

The aim and strategy of the study were explained to the children and their parents before data collection Children were assessed before application of the program by using the study tools. The interview was carried out in a special room.

The program was applied for children who meet the criteria of the study. The duration of the program was lasting 1year; the students were met three times weekly for three hours in each time.

Application of the program includes story activity, coloring, symbolization, shadowing and pyramid strategy.

Children were assessed immediately after implementation of the program by dyslexia, visual and auditory tests.
Application of the achievement rating scale for measuring the effect of the program on academic improvement.

\section{Statistical analysis}

The data were computerized and verified by using the SPSS (Statistical Package for Social Science) version 11.5 to perform tabulation and statistical analysis. Qualitative variables were described in frequency and percentages, while quantitative variables were described by mean and standard deviation. Analysis of collected data was done through the use of several statistical tests. 


\section{Results}

Table (1): Sociodemographic characteristics of the studied children $(n=100)$

\begin{tabular}{|c|c|c|c|c|c|}
\hline \multirow{2}{*}{ Variable } & \multicolumn{2}{|c|}{ Study group $(n=50)$} & \multicolumn{2}{|c|}{ Control group $(n=50)$} & \multirow{2}{*}{ P-value } \\
\hline & No. & $\%$ & No. & $\%$ & \\
\hline \multicolumn{5}{|l|}{ Age } & \multirow{3}{*}{0.832} \\
\hline$<10$ years & 34 & 68.0 & 33 & 66.0 & \\
\hline$\geq 10$ years & 16 & 32.0 & 17 & 34.0 & \\
\hline Mean \pm SD & \multicolumn{2}{|c|}{$9.00 \pm 1.13$} & \multicolumn{2}{|c|}{$9.04 \pm 1.26$} & 0.867 \\
\hline \multicolumn{5}{|l|}{ Sex } & \multirow{3}{*}{--} \\
\hline Male & 30 & 60.0 & 30 & 60.0 & \\
\hline Female & 20 & 40.0 & 20 & 40.0 & \\
\hline \multicolumn{5}{|l|}{ Grades } & \multirow{3}{*}{--} \\
\hline Grades $1-3$ & 20 & 40.0 & 20 & 40.0 & \\
\hline Grades 4-6 & 30 & 60.0 & 30 & 60.0 & \\
\hline \multicolumn{5}{|l|}{ Address } & \multirow{3}{*}{--} \\
\hline Rural & 26 & 52.0 & 26 & 52.0 & \\
\hline Urban & 24 & 48.0 & 24 & 48.0 & \\
\hline \multicolumn{5}{|l|}{ Socioeconomic class } & \multirow{4}{*}{0.082} \\
\hline High & 13 & 26.0 & 5 & 10.0 & \\
\hline Middle & 23 & 46.0 & 35 & 70.0 & \\
\hline Low/ Very low & 14 & 27.0 & 10 & 20.0 & \\
\hline
\end{tabular}

Table (2): Relationship between visual memory and age after application of the program among the dyslexic children.

\begin{tabular}{|c|c|c|c|c|}
\hline \multirow{3}{*}{ Visual memory test } & & \multicolumn{2}{|c|}{ Age } & \multirow{3}{*}{ P-value } \\
\hline & & $<10$ years & $\geq 10$ years & \\
\hline & & Mean \pm SD & Mean \pm SD & \\
\hline \multirow{2}{*}{ Visual discrimination } & Pre & $2.21 \pm 1.01$ & $2.63 \pm 1.54$ & 0.256 \\
\hline & Post & $7.09 \pm 1.88$ & $7.81 \pm 1.56$ & 0.187 \\
\hline \multirow{2}{*}{ Visual memory } & Pre & $2.65 \pm 1.23$ & $2.94 \pm 1.65$ & 0.489 \\
\hline & Post & $7.77 \pm 1.83$ & $8.25 \pm 1.57$ & 0.365 \\
\hline \multirow{2}{*}{ Visio-motor association } & Pre & $2.71 \pm 1.66$ & $3.00 \pm 1.67$ & 0.563 \\
\hline & Post & $7.65 \pm 1.65$ & $7.94 \pm 1.29$ & 0.538 \\
\hline \multirow{2}{*}{ Recognition test } & Pre & $2.97 \pm 1.75$ & $3.38 \pm 2.00$ & 0.470 \\
\hline & Post & $7.74 \pm 1.96$ & $8.44 \pm 1.32$ & 0.200 \\
\hline \multirow{2}{*}{ Total visual memory test } & Pre & $10.53 \pm 5.09$ & $11.94 \pm 5.97$ & 0.392 \\
\hline & Post & $30.24 \pm 6.72$ & $32.44 \pm 5.45$ & 0.258 \\
\hline
\end{tabular}

Table (3): Relationship between auditory memory and age after application of the program among the dyslexic children.

\begin{tabular}{|c|c|c|c|c|}
\hline \multirow{3}{*}{ Auditory memory test } & & \multicolumn{2}{|c|}{ Age } & \multirow{3}{*}{ P-value } \\
\hline & & $<10$ years & $\geq 10$ years & \\
\hline & & Mean \pm SD & Mean \pm SD & \\
\hline \multirow{2}{*}{ Auditory discrimination } & Pre & $2.50 \pm 1.60$ & $2.94 \pm 1.84$ & 0.395 \\
\hline & Post & $8.09 \pm 1.83$ & $8.75 \pm 1.44$ & 0.210 \\
\hline \multirow{2}{*}{ Auditory memory } & Pre & $2.88 \pm 1.39$ & $3.63 \pm 1.86$ & 0.121 \\
\hline & Post & $8.18 \pm 1.70$ & $8.75 \pm 1.34$ & 0.241 \\
\hline \multirow{2}{*}{ Auditory consequence } & Pre & $3.09 \pm 1.62$ & $3.75 \pm 2.18$ & 0.234 \\
\hline & Post & $8.03 \pm 1.75$ & $8.50 \pm 1.21$ & 0.337 \\
\hline
\end{tabular}




\begin{tabular}{|c|c|c|c|c|}
\hline \multirow{3}{*}{ Auditory memory test } & & \multicolumn{2}{|c|}{ Age } & \multirow{3}{*}{ P-value } \\
\hline & & $<10$ years & $\geq 10$ years & \\
\hline & & Mean \pm SD & Mean \pm SD & \\
\hline \multirow{2}{*}{ Auditory association } & Pre & $3.03 \pm 1.77$ & $3.00 \pm 1.86$ & 0.957 \\
\hline & Post & $8.06 \pm 1.72$ & $8.88 \pm 1.09$ & 0.089 \\
\hline \multirow{2}{*}{ Total auditory memory test } & Pre & $11.50 \pm 5.91$ & $13.31 \pm 7.12$ & 0.348 \\
\hline & Post & $32.35 \pm 6.74$ & $34.88 \pm 4.91$ & 0.188 \\
\hline
\end{tabular}

Table (4): Relationship between visual memory and sex after application of the program among the dyslexic children.

\begin{tabular}{|l|c|c|c|c|}
\hline \multirow{2}{*}{\multicolumn{2}{|c|}{ Visual memory test }} & \multicolumn{2}{|c|}{ Sex } \\
\cline { 3 - 5 } & & Male & Female & \multirow{2}{*}{ P-value } \\
\cline { 3 - 5 } & & Mean \pm SD & Mean \pm SD & \\
\hline \multirow{2}{*}{ Visual discrimination } & Pre & $2.60 \pm 1.25$ & $1.95 \pm 1.05$ & 0.061 \\
\hline \multirow{2}{*}{ Visual memory } & Post & $6.77 \pm 1.89$ & $8.15 \pm 1.31$ & $0.006^{*}$ \\
\hline \multirow{2}{*}{ Visio-motor association } & Pre & $3.20 \pm 1.32$ & $2.05 \pm 1.15$ & $0.003^{*}$ \\
\cline { 2 - 5 } & Post & $7.33 \pm 2.01$ & $8.80 \pm 0.62$ & $0.003^{*}$ \\
\hline \multirow{2}{*}{ Recognition test } & Pre & $3.07 \pm 1.78$ & $2.40 \pm 1.39$ & 0.165 \\
\cline { 2 - 5 } & Post & $7.37 \pm 1.71$ & $8.30 \pm 1.03$ & $0.034^{*}$ \\
\hline \multirow{2}{*}{ Visual memory test } & Pre & $3.73 \pm 1.91$ & $2.15 \pm 1.18$ & $0.002^{*}$ \\
\cline { 2 - 5 } & Post & $7.43 \pm 2.05$ & $8.75 \pm 0.91$ & $0.010^{*}$ \\
\hline
\end{tabular}

Table (5): Relationship between auditory memory and sex after application of the program among the dyslexic children.

\begin{tabular}{|c|c|c|c|c|}
\hline \multirow{3}{*}{ Auditory memory test } & & \multicolumn{2}{|c|}{ Sex } & \multirow{3}{*}{ P-value } \\
\hline & & Male & Female & \\
\hline & & Mean \pm SD & Mean \pm SD & \\
\hline \multirow{2}{*}{ Auditory discrimination } & Pre & $3.20 \pm 1.79$ & $1.80 \pm 1.06$ & $0.003^{*}$ \\
\hline & Post & $7.87 \pm 1.91$ & $8.95 \pm 1.19$ & $0.028 *$ \\
\hline \multirow{2}{*}{ Auditory memory } & Pre & $3.53 \pm 1.57$ & $2.50 \pm 1.40$ & $0.021 *$ \\
\hline & Post & $7.93 \pm 1.80$ & $9.00 \pm 0.97$ & $0.019 *$ \\
\hline \multirow{2}{*}{ Auditory consequence } & Pre & $3.73 \pm 2.02$ & $2.65 \pm 1.27$ & $0.038 *$ \\
\hline & Post & $7.73 \pm 1.78$ & $8.85 \pm 0.99$ & $0.014 *$ \\
\hline \multirow{2}{*}{ Auditory association } & Pre & $3.57 \pm 1.96$ & $2.20 \pm 1.06$ & $0.006^{*}$ \\
\hline & Post & $7.93 \pm 1.80$ & $8.90 \pm 0.97$ & $0.033^{*}$ \\
\hline \multirow{2}{*}{ Total auditory memory test } & Pre & $14.03 \pm 6.69$ & $9.15 \pm 4.39$ & $0.006^{*}$ \\
\hline & Post & $31.47 \pm 7.08$ & $35.70 \pm 3.71$ & $0.018^{*}$ \\
\hline
\end{tabular}


Table (6): Relationship between visual memory and socioeconomic status after application of the program among the dyslexic children.

\begin{tabular}{|c|c|c|c|c|c|}
\hline \multirow{3}{*}{ Visual memory test } & & \multicolumn{3}{|c|}{ Socioeconomic status } & \multirow{3}{*}{ P-value } \\
\hline & & High & Middle & Low/ very low & \\
\hline & & Mean \pm SD & Mean \pm SD & Mean \pm SD & \\
\hline \multirow{2}{*}{ Visual discrimination } & Pre & $2.62 \pm 1.39$ & $2.44 \pm 1.16$ & $1.93 \pm 1.07$ & 0.299 \\
\hline & Post & $7.31 \pm 1.93$ & $7.39 \pm 1.64$ & $7.21 \pm 2.04$ & 0.960 \\
\hline \multirow{2}{*}{ Visual memory } & Pre & $3.08 \pm 1.32$ & $3.04 \pm 1.55$ & $1.93 \pm 0.62$ & $0.029 *$ \\
\hline & Post & $7.85 \pm 2.23$ & $7.96 \pm 1.58$ & $7.93 \pm 1.64$ & 0.984 \\
\hline \multirow{2}{*}{ Visio-motor association } & Pre & $3.08 \pm 1.80$ & $3.09 \pm 1.86$ & $2.07 \pm 0.83$ & 0.152 \\
\hline & Post & $7.54 \pm 2.03$ & $7.74 \pm 1.32$ & $7.93 \pm 1.44$ & 0.811 \\
\hline \multirow{2}{*}{ Recognition test } & Pre & $3.62 \pm 1.85$ & $3.39 \pm 2.02$ & $2.14 \pm 1.03$ & 0.061 \\
\hline & Post & $7.85 \pm 2.12$ & $8.09 \pm 1.65$ & $7.86 \pm 1.83$ & 0.903 \\
\hline \multirow{2}{*}{ Total visual memory test } & Pre & $12.39 \pm 5.75$ & $11.96 \pm 5.94$ & $8.07 \pm 2.37$ & 0.053 \\
\hline & Post & $30.54 \pm 8.11$ & $31.17 \pm 5.36$ & $30.93 \pm 6.58$ & 0.961 \\
\hline
\end{tabular}

Table (7): Relationship between auditory memory and socioeconomic status after application of the program among the dyslexic children.

\begin{tabular}{|c|c|c|c|c|c|}
\hline \multirow{3}{*}{ Auditory memory test } & & \multicolumn{3}{|c|}{ Socioeconomic status } & \multirow{3}{*}{ P-value } \\
\hline & & High & Middle & Low/ very low & \\
\hline & & Mean \pm SD & Mean \pm SD & Mean \pm SD & \\
\hline \multirow{2}{*}{ Auditory discrimination } & Pre & $3.00 \pm 1.96$ & $2.83 \pm 1.61$ & $2.00 \pm 1.41$ & 0.235 \\
\hline & Post & $8.23 \pm 2.05$ & $8.48 \pm 1.47$ & $8.07 \pm 1.90$ & 0.782 \\
\hline \multirow{2}{*}{ Auditory memory } & Pre & $3.31 \pm 1.32$ & $3.44 \pm 1.88$ & $2.43 \pm 1.02$ & 0.149 \\
\hline & Post & $8.39 \pm 2.06$ & $8.35 \pm 1.27$ & $8.36 \pm 1.74$ & 0.998 \\
\hline \multirow{2}{*}{ Auditory consequence } & Pre & $3.85 \pm 1.52$ & $3.52 \pm 2.19$ & $2.43 \pm 1.02$ & 0.093 \\
\hline & Post & $8.15 \pm 2.08$ & $8.39 \pm 1.31$ & $7.86 \pm 1.61$ & 0.624 \\
\hline \multirow{2}{*}{ Auditory association } & Pre & $3.62 \pm 1.98$ & $3.22 \pm 1.91$ & $2.14 \pm 0.95$ & 0.074 \\
\hline & Post & $8.23 \pm 2.09$ & $8.39 \pm 1.41$ & $8.29 \pm 1.44$ & 0.956 \\
\hline \multirow{2}{*}{ Total auditory memory test } & Pre & $13.77 \pm 6.25$ & $13.00 \pm 7.17$ & $9.00 \pm 3.51$ & 0.091 \\
\hline & Post & $33.00 \pm 8.12$ & $33.61 \pm 5.15$ & $32.57 \pm 6.48$ & 0.887 \\
\hline
\end{tabular}

Table (8): Relationship between visual memory and residence after application of the program among the dyslexic children.

\begin{tabular}{|c|c|c|c|c|}
\hline \multirow{3}{*}{ Visual memory test } & & \multicolumn{2}{|c|}{ Residence } & \multirow{3}{*}{ P-value } \\
\hline & & Rural & Urban & \\
\hline & & Mean \pm SD & Mean \pm SD & \\
\hline \multirow{2}{*}{ Visual discrimination } & Pre & $2.39 \pm 1.27$ & $2.29 \pm 1.16$ & 0.788 \\
\hline & Post & $7.27 \pm 1.93$ & $7.38 \pm 1.69$ & 0.838 \\
\hline \multirow{2}{*}{ Visual memory } & Pre & $2.81 \pm 1.36$ & $2.67 \pm 1.40$ & 0.720 \\
\hline & Post & $7.81 \pm 1.92$ & $8.04 \pm 1.57$ & 0.641 \\
\hline \multirow{2}{*}{ Visio-motor association } & Pre & $2.81 \pm 1.74$ & $2.79 \pm 1.59$ & 0.973 \\
\hline & Post & $7.58 \pm 1.81$ & $7.92 \pm 1.18$ & 0.440 \\
\hline \multirow{2}{*}{ Recognition test } & Pre & $3.04 \pm 1.82$ & $3.17 \pm 1.86$ & 0.806 \\
\hline & Post & $7.85 \pm 2.20$ & $8.08 \pm 1.25$ & 0.645 \\
\hline \multirow{2}{*}{ Visual memory test } & Pre & $11.04 \pm 5.55$ & $10.92 \pm 5.28$ & 0.937 \\
\hline & Post & $30.50 \pm 7.29$ & $31.42 \pm 5.31$ & 0.616 \\
\hline
\end{tabular}


Table (9): Relationship between auditory memory and residence after application of the program among the dyslexic children.

\begin{tabular}{|c|c|c|c|c|}
\hline \multirow{3}{*}{ Auditory memory test } & & \multicolumn{2}{|c|}{ Residence } & \multirow{3}{*}{ P-value } \\
\hline & & Rural & Urban & \\
\hline & & Mean \pm SD & Mean \pm SD & \\
\hline \multirow{2}{*}{ Auditory discrimination } & Pre & $2.89 \pm 1.90$ & $2.38 \pm 1.38$ & 0.287 \\
\hline & Post & $8.23 \pm 2.01$ & $8.38 \pm 1.41$ & 0.772 \\
\hline \multirow{2}{*}{ Auditory memory } & Pre & $3.31 \pm 1.54$ & $2.92 \pm 1.61$ & 0.385 \\
\hline & Post & $8.31 \pm 1.81$ & $8.42 \pm 1.38$ & 0.813 \\
\hline \multirow{2}{*}{ Auditory consequence } & Pre & $3.35 \pm 1.65$ & $3.25 \pm 2.03$ & 0.854 \\
\hline & Post & $8.08 \pm 1.87$ & $8.29 \pm 1.27$ & 0.640 \\
\hline \multirow{2}{*}{ Auditory association } & Pre & $2.89 \pm 1.66$ & $3.17 \pm 1.93$ & 0.581 \\
\hline & Post & $8.23 \pm 1.84$ & $8.42 \pm 1.28$ & 0.683 \\
\hline \multirow{2}{*}{ Auditory memory test } & Pre & $12.42 \pm 6.24$ & $11.71 \pm 6.50$ & 0.693 \\
\hline & Post & $32.85 \pm 7.27$ & $33.50 \pm 5.12$ & 0.717 \\
\hline
\end{tabular}

Table (1) : shows that the studied sample consisted of 50 children, $60 \%$ were boys while $40 \%$ were girls. The mean age was $9.00 \pm 1.13$ years, $68 \%$ at age $<10$ years old and $32 \%$ at age $\geq 10$ years old and age ranged from 7-11 years. As regard school grades, most of the studied children $40 \%$ at $1-3$ grade and $60 \%$ at 4-6 grade. As regard residence of the studied group 52\% from rural areas and $48 \%$ from urban areas, the studied children (46\%) are in the middle socioeconomic status and there is no significant difference between the studied and control group as regard thesociodemographic characteristics.

Table (2) : relationship between visual memory and age after application of the program among the dyslexic children, it shows that, there is no statistical difference as regard the age and visual memory test and its entire component after the application of the program.

Table (3) : shows relationship between auditory memory test and age after application of the program among the dyslexic children, it shows that, there is no statistical difference as regard the age and auditory memory test and its entire component except in auditory association after the application of the program.

Table (4) : shows relationship between visual memory and sex after application of the program among the dyslexic children, it shows that, there is a statistical difference as regard sex and component of visual memory test after the application of the program in which girls had a higher scores in visual memory test and all subtests than boys after the application of the program.

Table (5) : shows relationship between auditory memory and sex after application of the program among the dyslexic children, it shows that, there is a statistical difference as regard sex and component of auditory memory test after the application of the program in which girls had a higher scores in auditory memory test and all subtests than boys after the application of the program.

Table (6) : shows relationship between visual memory and socioeconomic status after application of the program among the dyslexic children, it shows that, there is no statistical difference as regard socioeconomic class and visual memory test and its entire components after the application of the program.

Table (7) : shows relationship between auditory memory and socioeconomic status after application of the program among the dyslexic children, it shows that, there is no statistical difference as regard socioeconomic class and auditory memory test and its entire components after the application of the program.

Table (8) : shows relationship between visual memory and residence after application of the program among the dyslexic children, it shows that, there is no significant difference as regard residence and visual memory test and its entire components after the application of the program.

Table (9) : shows relationship between auditory memory and residence after application of the program among the dyslexic children, it shows that, there is no significant difference as regard residence and auditory memory test and its entire components after the application of the program.

\section{Discussion}

Developmental reading disorder is not easy to imagine, especially by people who read easily, some children experience reading as a continuous struggle in spite of the fact that they are intelligent and attend good schools. Discrepancy and surprise are the hallmarks of these children's lives. Parents and teacher of such a child will often express a surprise at 
the presence of all intellectual children's abilities despite very limited ability to read, those estimated $3 \%$ to $7 \%$ of school-age (Charnow, 2012).

In the present study the mean age of children was $9.00 \pm 1.13$ years old with range from $7-11$ years old. This is similar to what was reported by Shapiro et al., (2012) who reported that reading disabilities detected at an early school- age, approximately after 7 years when awaited the child's inadequate performance in school and added that the preschool identification of reading disabilities remains extremely difficult and those attempts to improve early identification of reading disability have focused on new electrophysiological technology to define disordered brain mechanisms, so dyslexia can't be diagnosed before the age of 7 years and always takes the range of 7-15 years old. Also the study of Burt\& Fury, (2013) confirms the present study findings, when demonstrated that in Egypt, where Arabic is the national and official language, the prevalence of specific reading disability is $2.8 \%$ and that far lower among elementary school children.

Regarding sex, the present study estimated about $60 \%$ of the studied children were males. That is consistent with many authors whose expressed that there is difference in the prevalence of dyslexia in both sexes such as the study of Farrage et al., (2010) found that there was a higher incidence of dyslexia among boys than girls with male to female ratio of 2.7: 1. Also, the study of Shaywitz et al., (2010) reported that the prevalence of reading disability based on the school identification is two to four times in boys than in girls in which the ratio of males to females has varied from 2: 1 to 5: 1 . In additional to Finucci\& Childs, (2011) found that increased prevalence of reading disability in boys compared with girls in specific school for reading disabled children. Moreover, Defries et al., (2012) found that dyslexia was 3 to 4 times commoner among boys than girls.

In a trial to explain this high incidence of dyslexia among boys than girls, Miles et al., (2012) argued that girls mature earlier than boys, then he suggested a genetic factor to be involved since it is hard for other factors to explain an imbalance of this magnitude. Also, Critchly\& Pennington- Smith, (2012) supported this difference and attributed to anomalies in sex chromosomes. However, Shaywitz et al., (2012) provided an explanation for the excess of boys with reading disability in school identification sample, he related that to the nature of boys as significantly more active, more inattentive, less dexterous and having more problems in behavior, language, and academics than their females beers.

While this findings disagree with some studies showing no significant differences in the rate of reading disabilities between both sexes, these studies are restricted to sample of young children in the fifth grade or lower (Johnson et al., 2011). Genschwind\& Galaburda, (2012) also contradicts with the current study findings when added that males, in general have superior cognitive functions mediated by the right cerebral hemisphere so dyslexia is less common among them.

In the present study most of the dyslexic children in the middle socioeconomic status and came equally from urban and rural areas. These findings agree with the study of Kolb\& Whishaw, (2012) reported that the incidence of reading disability is very high in low and middle socioeconomic status children than in high socioeconomic. They explained that by the poor environmental condition contribute to obstruct the part of oral expression and reading ability. The study of Elbeheri et al., (2010) emphasizes and confirm these findings when demonstrated that most of dyslexic Egyptian's children in low and middle socioeconomic status, they found that rural children at higher risk than urban children related to the effect of new technology in child's ability to read.

The Dyslexic Training Program which made through Orton- Gillingham- derived method provided significant gains in the ability of dyslexic children to decode none sense words, word recognition and reading comprehension when compared with the control studied in reading programs and researched average level, these findings are consistent with other recent evidence supporting the efficacy of intensive explicit phonologically based training.

Haywood, (2009) tappzolog \& Feuerstein, (2010) Bradley\& Bryant, 2011 and Das et al., (2012) showed that cognitive stimulation in early childhood could be effective and cognitive training has improved intellectual performance. This ultimate purpose of cognitive remediation is to improve specific cognitive processes that underlie academic skills such as reading words. Also the study of Elstein, (2012) and the study of Mender et al., (2012) found that the scores following training program for perceptual functions skills are significantly better. Moreover, the study of Das et al., (2012) showed that cognitive training techniques improve cognitive deficits such as successive processing and short term visual memory.

The current study findings highlighted on the significant difference between males and females in all tests after the application of program in which females had a higher scores than males. This issue was hotly debated by the study of Maccoby\& Jacklin, (2012) which showed that there was a cognitive sex differences on verbal, visuospatial and mathematical processes, in general females are perceived as outperform males in all visuospatial, 
quentative tasks, tasks require the use of language, memory tasks that require recall of verbal material or material that can be encoded verbally (e.g. avisual memory tasks that use pictures that can be easily labeled or named), digit span tasks and word span tasks and explained that related to possible biological origins.

Also, it was noticed in researches concerning reading development that males and females rely on different linguistic strategies for instance, Liberman \& Mann, 2013, Bakker\& Moerland, (2013) reviewed that females advanced to more sophisticated phonological decoding strategies prior to males, similarly,

At the same point, the study of Tallal\& Fitch, (2013) in a trial to explain this aspect, related that to the effect of sex hormones in which the levels of females hormones appear to improve the verbal skills whereas increased concentration of males hormones especially testosterone reduce the verbal ability in both sex, testosterone believed to have an effect on the development of the planum temporale (PT), this is a language related cortical area concerned with the perception of speech sounds and is located in the superior surface of the temporal lobe ( supratemporal region of the auditory association cortex). High androgen levels are only correlated with increased spatial skills in females, the hormonal effects on brain organization and cognition account for the increased preponderance of males.

In the light of the attempts to explain the current cognitive sex difference, the study of Wolf\& Kirschbaum, (2013) support the idea that cognitive function are organized differently within male and female brain in which the nerve fibers connect the left and right hemisphere in females which used to transfer information between the two halves of the female brain than there is the two halves of the male brain. Similarly, Bakker\& Moerland, (2013) hypothesized that differences in reading development and explained that result from persistent use of right hemispheric, visuospatial approaches to reading in males and the untimely use of the left hemisphere linguistic reading strategies in females. Kandel \& Tsuo, (2014) extended these hypotheses by suggesting the method of instruction, best suited to the different sexes, they maintained that the whole word method of reading instruction was more compatible with cognitive style of most boys, whilst girls procured greater advances in reading via phonics instruction. Female learning style is more congruous with linguistic or phonic approaches while male learning style is more reliant on visual strategies.

With my respect to the study of Manis et al., (2012) which disagree with the current study findings when showed that dyslexic children didn't show an increase of performance following visual- semantic instruction and whether dyslexic or non- dyslexic females didn't demonstrate greater improvements in spelling ability. Dyslexic children instructed by phonics method, males showed greater advances when instructed via a visual- semantic technique.

Dyslexic children's cognitive abilities and school achievement are deeply affected by parental socioeconomic status (SES) and residence (Hanson et al., (2012) Hackman et al., (2013) Ho et al., (2013) \& Gianaros et al ., 2013). That have never been clear in the current study findings in which there was no significant difference as regard the level of socioeconomic status on the child improvement or reaction to the program, those numerous studies summarize that lower cognitive performance especially language affect on the child's neural structures according to both volume and surfacebased morphometry there is an association between SES and the brain anatomy, the lower SES, the smaller volumes of gray matter in bilateral hippocampus, middle temporal gyri, left fusiform and right inferior occipito- temporal gyri,. Moreover, they identify local gyrification effects in anterior frontal regions develop in lower SES children. As well as the current study findings the study of Tomalski et al., (2013) showed that no significant association between SES and all cognitive functions of dyslexic children (visual, auditory, oral language, recognition, spelling, phonological processing and decoding).

The National institute of child Health and Human Development, 2000; Togesen, (2012) reported that the age of dyslexic children doesn't play any role in the improvement of their problems despite of intensive instruction and accurate programs and they are still slow readers. That clearly appeared in the current study findings in which there was no significant difference as regard the age of the studied children and all tests after the application of the program.

On the other hand the study of Bear et al., (2011) demonstrated that the age of dyslexic children influence on their progress in oral language skills, vocabulary knowledge, reading comprehension, spelling, word recognition, decoding and that with adequately intensive instruction, young dyslexic children often have delays in language development, but their higher- level language skills are usually ageappropriate by the time. Furthermore, the study of Gianaros et al., (2011) noticed that although intensive evidence- based remediation intervention can markedly improve reading accuracy in older reading disabled children; they have been significantly less effective in closing the fluency gap. Also the phonologically driven linguistic treatment studies indicated that the younger child, the more 
explicit of intervention must be; the older child and the more severe the impairment, the more intensive the treatment and the longer its duration must be (Snow et al., 2011).

\section{Conclusion}

Based on the results of the present study it can be concluded that, Sex only plays an important role in improving the cognitive function of dyslexic children in which girls outperform boys. So intensive attention should be given to male dyslexic children to improve their cognitive function.

\section{Recommendations}

From the previous conclusion, the following recommendations are suggested

1. Nurses as a care giver to dyslexic children should focus on cognitive aspects as well as psychological aspects of dyslexic children.

2. Provide a variety of cognitive training programs for dyslexic children available in schools, hospitals, clinics and homes.

3. Early screening, diagnosis and detection for dyslexic children in schools help in engagement of them in available programs to enhance their future academic achievement.

4. Intensive attention should be given to male dyslexic children to improve their cognitive function.

\section{References}

1. Bakker, D., \& Moerland, R., (2013): Are there brain-tied sex differences in reading?

2. Bear, D., Invernizzi, M., Templeton, S., \& Johnston, F., (2011): Words their way: Word study phonics, vocabulary, and spelling instruction. (3 ed.). Upper Saddle River, NJ: Merrill Publishing.

3. Bradley, L., \& Bryant, P., (2011): Categorizing sounds and learning to read - a causal connection. Nature, 301 (5899), 419421.

4. Burt, J., \& Fury, M., (2013): Spelling in learning disabled children: The role of reading skills and experience. Reading and Writing: An Interdisciplinary Journal, 131-30.

5. Charnow D., (2012): Developmental reading disorder. Comprehensive Textbook of Psychiatry. Vol. II, $5^{\text {th }}$ edn. PP: 1790-1796. Kaplan HI and Sadock BJ. Williams and Wilkins, Baltimore Hong Kong, London.

6. Clark, D., \& Mather, J., (2013): Dyslexia: theory and practice of remedial instruction (2nd ed.). Baltimore, MD: York Press.
7. Critchley, M., \& penningtin-smith, (2012): Developmental dyslexia. London, UK: William Heinemann Medical Books Limited.

8. Das J., Mishra R., \& Kirby J., (2012): Cognitive patterns of dyslexia: Comparison between groups with high and average non verbal intelligence. Journal of Learning Disabilities 27: 235-242.

9. De Fries J., Singer S., Foch T., \& Lewitter F., (2012): Failial Nature of Reading Disability, British Journal of Psychiatry 2:36-367.

10. Debray P., \& Ritzen R., ( 2011): Diagnosis and natural history of dyslexia in children. Child Health De. 5: 27-9.

11. Denton C., Mathes P., (2014): Intervention for struggling readers, in Foorman BR (ed): Preventing and Remediating Reading Difficulties: Bringing Science to Scale. Timonium, MD, York Press, 229-252.

12. Dykman, R., (1993): Auditory and visual memory scale. Journal of Learning Disabilities, 13,309-318.

13. Elbehairy A., Abdel Kader F., (1998): Arabic version of auditory and visual memory tests, El-Nahdah, in press.

14. Elstein A., (2012): Effects of physical education on the physical fitness, social adjustment and self- concept of learning disabled students (doctoral dissertation) Philadelphia: Temple University.

15. Elstein A., (2012): Effects of physical education on the physical fitness, social adjustment and self- concept of learning disabled students (doctoral dissertation) Philadelphia: Temple University.

16. Fahmey \& Elisherbinim, (1984): Socioeconomic status scale, Faculty of education, department of psychology, Assiut University, El-Nahdah, in press.

17. Familial nature of reading disability. British Journal of Psychiatry 2:361-367.

18. Farrage A., El- Behery A., \& Kandil M., (2010): Prevalence of specific reading disability in Egypt. Lancet 8:837-839.

19. Feurerstein R., (2010): The Dynamic Assessment of retarded performance: The learning potential assessment device, theory, instruments \& techniques. Baltimore, University Park Press, Cited in Das et al., (2012).

20. Finucci J., \& Childs B., (2011): Are there really more dyslexic boys than girls? In Ansara A., Geshwind N., Galaburda A., Albert M. and Gartrell N. (eds.) Gender Differences in Dyslexia. Towson, Md: Orton Dyslexia 
Society; PP.1-9.

21. Genschwind N., \& Galaburda A., (2012): Cerebral lateralization. Cambridge MA. The MIT Press.

22. Gianaros, P., Horenstein, J., Cohen, S., Matthews, K., Brown, S., Flory, J., Critchley, H., Manuck, S., \& Hariri, A., (2011): Perigenual anterior cingulate morphology covaries with perceived social standing. Social Cognitive \& Affective Neuroscience, 2 (3), 161-173.

23. Gianaros, P., Horenstein, J., Hariri, A., Sheu, L.K., Manuck, S., Matthews, K., \& Cohen, S., (2012): Potential neural embedding of parental social standing. Social Cognitive \& Affective Neuroscience, 3 (2), 91-96.

24. Gordon, J., (2008): Spelling interventions: A review of literature and implications for instruction for students with learning disability. Learning Disabilities Research and Practise, 8,175-181.

25. Hackman, D., Farah, M., Meyer, M. S., (2010): Socioeconomic status and The developing brain. Trends in Cognitive Sciences, 13(2), 65-73.

26. Hall, J.,. \& Kimura, D., (2012): Sexual orientation and performance on sexually dimorphic motor tasks. Archives of Sexual Behavior, 24,395-407.

27. Hallahan D., Kauffman J., \& Lioyed J., (2012): Introduction to Learning Disabilities $\left(2^{\text {nd }}\right.$ ed.). Englewood Cliffs, N., Prentice Hall.

28. Hanson JL, Chandra A, Wolfe BL, Pollak SD (2012): Association between income and the hippocampus. Plos ONE 6 (5): e18712.

29. Haywood H., \& Tappzolog J., (2009): Experience and the development of adaptive behavior. In N., Ellis (Eds.) International Review of Research in Mentyal Retardation. PP. 109-151. New York: Academic Press. Cited in Das (2012).

30. Haywood H., \& Tappzolog J., (2009): Experience and the development of adaptive behavior. In N., Ellis (Eds.) International Review of Research in Mentyal Retardation. PP. 109-151. New York: Academic Press. Cited in Das (2012).

31. Helmuth, L., (2014): Dyslexia: Same Brains, Different Language. Science, 291, 2064-2065.

32. Hiebert, E., Taylor, B., (2014): Beginning Reading Instruction: Research on Early Interventions. In Kamil, M., Mosenthal, P. B., Pearson, P., Barr, R., Handbook of Reading Research, Vol III. Mahwah N., Lawrence Erlbaum.
33. Ho, C., S-H.; Chan, D., W-O. Lee, S., Tsang, S., Luan, V., (2014). Cognitive Profiling and Preliminary Subtyping in Chinese Developmental Dyslexia. Cognition, 91, 4375.

34. Hynd, G., \& Obrzut, J., (2009): Development iof reciprocal hemispheric inhibition in normal and learning - disabled children. The Journal of General Psychology, 104: 203-12. Cited by Coplin\& Morgan (2012).

35. Johnson D., (2011): Review of Research on Specific Reading, Writing and Mathematic disordes. Part II, PP. 79-163. Learning disabilities: Proceedings of the National Conference. Edited by Kavanagh JF and Truss TJ. York Press, Pakton, Maryland.

36. Kandel, G., \& Tsao, Y., (2014). Implications of neuropsychological findings for

37. Kinsboune M., \& Warringon E., (2010): The developmental Gersmann syndrome. In: The Disabled Reader. Edited by J. Money. Johns Hopkins Press, Baltimore. Cited by Myklebust H.R. (2012). Kirschbaum, (2013).

38. Liberman, I., \& Mann, V., (2012). Should reading instruction and remediation vary with the sex of the child? In A Ansara (Ed), Sex Differences in Dyslexia. US: The Orton Dyslexia Society.

39. Lyon, G., \& Gore, J., (2012): Neural systems for compensation and persistence: young adult outcome of childhood reading disability. Biol. Psychiatry 54, 25-33.

40. Maccoby E., \& Jacklin C., (2012): The Psychology of Sex Differences. Stanford, CA: Stanford University Press.

41. Manis, F. R., Seidenberg, M. S., Doi, L. M., McBrideChang, C., \& Petersen, A. (2011): On the bases of two subtypes of development dyslexia. Cognition, 58 (2), 157-195.

42. Mender J., Kerr R., \& Orlick T., (2012): Cooperative games program for learning disabled children. Int J Sports Psychol 13: 222-233.

43. Miles, C., Green, R., Sanders, G., \& Hines, M., (2012): Estrogen and memory in a transsexual population. Hormones and Behaviour, 34,199-208.

44. Nasra G., (2006): Arabic version of dyslexic diagnostic scale, El-Nahdah, in press.

45. Nix, G., \& Shapiro, J., (2009): Auditory perceptual processing in learning assistance children: Apreliminary report. Journal of Research Reading 9(2): 92-102.

46. Reid D., ( 2007): Learning disabilities and the cognitive developmental approache. In D., 
Reid (ed.), Teaching the Learning Disabled. Acognitive Developmental Apperoach. PP: 2946. Boston, Allyn and Bacon.

47. Rutter, M., Tizard, J., \& Whitmore, K., (2012): Education, Health and Behaviour. London: Longmans.

48. Shapiro B., Gallico R., Slaghuis W., (2012): Learning disabilities. Pediatric Clinics of North America 40 (3): 491-505.

49. Shaywitz, S., Shaywitz, B., Fulbright, R., Skudlarski, P., Mencl, W. E., Constable, R. T., Pugh, K. R., Holahan, J. M., Marchione, K. E., Fletcher, J. M

50. Shaywitz, S., Fletcher, J., Holahan, J., Shneider, A., Marchione, K., Stuebing, K., Francis, D., Pugh, K., Shaywitz, B., (2010): Persistence of Dyslexia: The Connecticut Longitudinal Study at Adolescence. Pediatrics, 104, 1351-1359.

51. Snow C., Burns M., Griffin P., (2011): Preventing Reading Difficulties in Young Children. Washington, DC, National Academy Press.

52. Tallal, P., \& Fitch, R., (2013): Neurobiological basis of speech: A case for the preeminence of temporal processing. Irish Journal of Psychology, 16 (3), 194-219.

53. Tappzolog A., \& Feurerstein B., (2010): How Phonological Awareness Training: A New Approach to Phonics Teaching. Dyslexia, 2, 101-120.

54. The reading instruction of boys and girls. In A., Ansara (Ed), (2011) : Sex Differences in Dyslexia. US: The Orton Dyslexia Society.

55. Tomalski P., Johnson M., (2013): The effects of early adversity on the adult and

56. Torgesen, J., Alexander, A., Wagner, R., Rashotte, C., Voeller, K., Conway, T., (2012) : P., Intensive Remedial Instruction for Children with Severe Reading Disabilities: Immediate and Long-Term Outcomes from Two Instructional Approaches. Journal of Learning Disabilities, 34, 33-58.

57. Van Hout A., (2012): Dyslexia, neurolinguistic, diagnostic and remediation methods. Child Health Development. Vol. 5, PP: 157-163.

58. Wolf, O., \& Kirschbaum, C., (2013). Endogenous estradiol and testosterone levels are associatedw ith cognitive performancei $n$ older women \& men. Hormones and Behaviour, 41,259-266. 